\title{
Comparative cost-effectiveness analyses of cardiovascular magnetic resonance and coronary angiography combined with fractional flow reserve for the diagnosis of coronary artery disease
}

Karine Moschetti ${ }^{1,2^{*}}$, David Favre ${ }^{1}$, Christophe Pinget ${ }^{1,2}$, Guenter Pilz ${ }^{3}$, Steffen E Petersen ${ }^{4}$, Anja Wagner ${ }^{5}$, Jean-Blaise Wasserfallen ${ }^{1,2}$ and Juerg Schwitter ${ }^{6}$

\begin{abstract}
s
Background: According to recent guidelines, patients with coronary artery disease (CAD) should undergo revascularization if significant myocardial ischemia is present. Both, cardiovascular magnetic resonance (CMR) and fractional flow reserve (FFR) allow for a reliable ischemia assessment and in combination with anatomical information provided by invasive coronary angiography (CXA), such a work-up sets the basis for a decision to revascularize or not. The cost-effectiveness ratio of these two strategies is compared.

Methods: Strategy 1) CMR to assess ischemia followed by CXA in ischemia-positive patients (CMR + CXA), Strategy 2) CXA followed by FFR in angiographically positive stenoses (CXA + FFR). The costs, evaluated from the third party payer perspective in Switzerland, Germany, the United Kingdom (UK), and the United States (US), included public prices of the different outpatient procedures and costs induced by procedural complications and by diagnostic errors. The effectiveness criterion was the correct identification of hemodynamically significant coronary lesion(s) (= significant CAD) complemented by full anatomical information. Test performances were derived from the published literature. Cost-effectiveness ratios for both strategies were compared for hypothetical cohorts with different pretest likelihood of significant CAD.

Results: CMR + CXA and CXA + FFR were equally cost-effective at a pretest likelihood of CAD of $62 \%$ in Switzerland, $65 \%$ in Germany, $83 \%$ in the UK, and 82\% in the US with costs of CHF 5'794, € 1'517, £ 2'680, and \$ 2'179 per patient correctly diagnosed. Below these thresholds, CMR + CXA showed lower costs per patient correctly diagnosed than CXA + FFR.

Conclusions: The CMR + CXA strategy is more cost-effective than CXA + FFR below a CAD prevalence of 62\%, 65\%, $83 \%$, and $82 \%$ for the Swiss, the German, the UK, and the US health care systems, respectively. These findings may help to optimize resource utilization in the diagnosis of CAD.
\end{abstract}

Keywords: Cost-effectiveness analysis, Coronary artery disease, Cardiovascular magnetic resonance, Coronary angiography, Fractional flow reserve, Decision making

\footnotetext{
*Correspondence: karine.moschetti@chuv.ch

'Institute of Health Economics and Management (IEMS), University of

Lausanne, Route de Chavannes 31, VIDY, 1015 Lausanne, Switzerland

${ }^{2}$ Technology Assessment Unit (UET), University Hospital (CHUV), Lausanne,

Switzerland

Full list of author information is available at the end of the article
} 


\section{Background}

In many countries, cardiovascular diseases are the leading cause of morbidity and also of loss of quality of life. In particular, coronary artery disease (CAD) constitutes a major public health problem. In Europe the total costs of CAD and stroke were estimated at 49 billion Euros in the year 2008 [1] and for the United States these costs were estimated as high as 156 billion dollars [2]. It is well established that patients with no evidence of myocardial ischemia have low cardiac events rates, even when invasive coronary angiography (CXA) demonstrates lesions of intermediate severity [3,4]. In addition, patients without ischemia can be treated safely with medical therapy $[5,6]$ thereby reducing the total costs of patient management [7]. On the other hand, randomized trials e.g. in diabetic patients demonstrated a survival benefit of patients with ischemia being treated by revascularization versus medical treatment alone [8]. Accordingly, recent guidelines recommend to revascularize patients if a relevant burden of myocardial ischemia is present (i.e. proximal vessel(s)) with a positive fractional flow reserve (FFR) and/or $>10 \%$ of myocardium ischemic [9] or $\geq 2$ ischemic segments in cardiovascular magnetic resonance (CMR) perfusion examinations [10].

Nevertheless, neither vessel anatomy nor presence or absence of ischemia is the factor that will exclusively decide on revascularizations. Symptoms, co-morbidities and other factors have to be taken into account before a treatment decision is made. Thus, the current analysis was undertaken to assess the cost-effectiveness to acquire information (significant ischemia and full anatomical information) relevant for decision making, but did not include the costs for all information needed to manage patients with CAD. Also, we do not know whether a large ischemia burden is directly related to adverse effects, whether it represents a marker of higher risk for occlusion of a severe stenosis that causes ischemia, or whether more severe ischaemia is simply a marker of more extensive atherosclerosis and more vulnerable plaques that go along with a worse outcome. Large trials such as ISCHEMIA and others [11] will hopefully improve our knowledge in a near future on how to treat ischemic patients. Despite this current lack of a detailed understanding of the underlying mechanisms that link ischemia to outcome, current guidelines recommend an ischemia-based approach for decision making in patients with CAD. Therefore, the aim of the current study was to assess the cost-effectiveness of two diagnostic strategies that are ischemia-based and provide both full anatomical and functional evaluation of CAD, which are the basis for a revascularization procedure.

A variety of new imaging techniques allow for such a combined anatomical and functional assessment of $\mathrm{CAD}$, and as a result, the selection of the optimum test becomes more and more challenging. The choice of cardiovascular imaging techniques should consider both, their clinical benefits for the patients as well as the costs and cost-effectiveness compared to others. Invasive coronary angiography (CXA) remains the reference for the morphological assessment of CAD and it is often used in daily practice as a first line test, e.g. in patients with a positive treadmill test. While this strategy is not recommended by current guidelines, the advent of the FFR measurement to assess the hemodynamic significance of coronary artery stenoses [12] may even increase the attractivity to use invasive CXA as a first line test, as it can be easily combined with FFR in case of intermediate stenoses. Also, the FFR results were highly predictive for patient outcome $[13,14]$ and the combination of CXA with FFR was more cost-effective than a CXA-only approach for the treatment of CAD [15]. Accordingly, recent guidelines recommend using FFR to correctly identify lesions that should undergo percutaneous coronary interventions (PCI) [9]. However, the invasive nature and radiation exposure of CXA and FFR limit their usefulness in a screening process [16]. Considering the fact that CXA is still extensively used in many industrialized countries as an early step in the work-up of suspected CAD $[17,18]$, and further considering that FFR is recommended in recent guidelines, the combination of CXA + FFR was one diagnostic strategy to be assessed in the current study with respect to its cost-effectiveness.

As an alternative to the FFR measurement, perfusion CMR has emerged as a robust non-invasive technique for the evaluation of myocardial ischemia [19-22]. Furthermore, recent studies demonstrated the excellent prognosis of patients with known or suspected CAD, when perfusion-CMR was normal [23-25]. Accordingly, in the present study, the cost-effectiveness of a combination of CMR + CXA was compared with that of a CXA + FFR strategy.

In the current economic context, the health care systems have to be economically sustainable while preserving high quality medical standards. Consequently, in the following study we estimated the costs of the two different strategies relative to their effectiveness to 1 ) correctly diagnose the presence of relevant ischemia (= significant $\mathrm{CAD}$ ) and 2) to yield full anatomical information of the coronary vasculature in case of ischemia. In particular, the cost-effectiveness of the two strategies was compared when applied to patient populations with varying $C A D$ pre-test probabilities. Strategy 1 consists of a CMR examination to assess ischemia followed by CXA in ischemiapositive patients $(\mathrm{CMR}+\mathrm{CXA})$. This strategy yields complete information on myocardial ischemia and coronary anatomy. Strategy 2 consists of a CXA in all patients followed by a FFR test in patients with intermediate stenoses on CXA (CXA + FFR). Finally, the cost- 
effectiveness ratios of the two strategies were calculated for the health care systems in Switzerland, Germany, the United Kingdom, and the United States.

\section{Methods}

Using a mathematical model, we compared the costeffectiveness of 2 algorithms for diagnosing the presence of hemodynamically significant coronary lesion(s) (= significant $\mathrm{CAD})$ for hypothetical patient cohorts characterized by different pretest likelihood of CAD ( $\left.\mathrm{P}_{\text {isch }}\right)$ : 1) A perfusion CMR to assess myocardial ischemia before referring positive patients to CXA and 2) A CXA combined with an FFR in patients with angiographically positive stenoses (see also Figure 1).

\section{Model characteristics}

The model is based on Bayes' theorem and consequently assesses cost-effectiveness ratios of strategies in hypothetical patient cohorts with different pretest likelihoods of disease [26]. The mathematical model was initially suggested by Paterson and co-workers [27] and was later on applied by others [28-30]. The simulation approach has the advantage to allow the evaluation of diagnostic algorithms for patients with different pretest likelihoods of CAD regardless of currently accepted and applied clinical strategies to detect CAD. In order to determine the pretest likelihood of CAD in patients, the same testing procedures would precede both strategies, i.e. CMR + CXA and CXA + FFR, implying the same costs for both strategies. Therefore, these "upstream" costs need not to be considered in the model. Similarly, once a treatment decision is made, based on either diagnostic strategy the same treatment costs will occur and therefore, these "downstream" costs were not considered either in the model. No ethics approval was obtained for this study as it is based on simulation model calculations and therefore no patients data from our institution were required. Calculations were performed with Microsoft Office Excel 2007 software.

\section{Cost-effectiveness analysis \\ Definition of effectiveness}

In the present study, the criterion of effectiveness is the ability to accurately identify those patients with one or more hemodynamically significant coronary lesion(s) (=significant

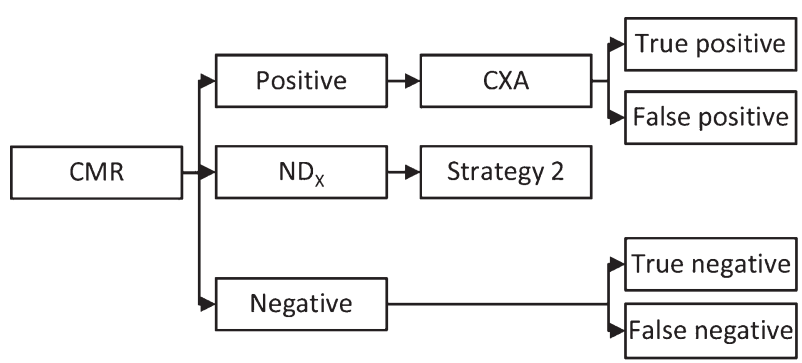

Strategy $1\left(\right.$ CMR+CXA) involves a perfusion CMR to assess myocardial ischemia $\left(\mathrm{P}_{\text {isch }}\right)$ before referring positive patients to coronary angiography (CXA). This latter test either confirms or rejects the CMR diagnosis and adds anatomical information in true positive patients which is required for the final diagnosis. Patients with non diagnostic CMR (NDx) cross over to strategy 2. False-negative patients due to diagnostic errors are at risk for complications (e.g. myocardial infarction) due to the undetected and thus in-correctly treated CAD.

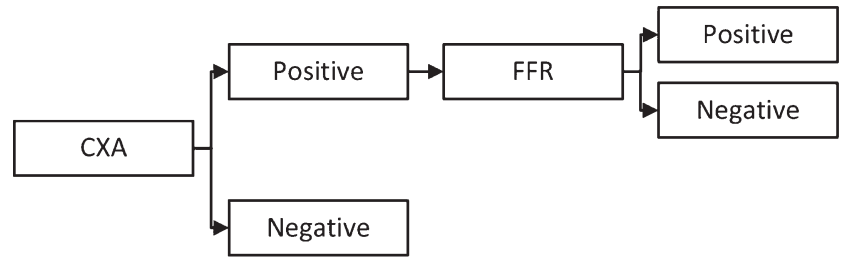

In strategy 2 (CXA+FFR), a CXA is performed in all patients and is combined with an FFR test in patients with angiographically positive stenoses, i.e. $\geq 50 \%$ diameter reduction.

Figure 1 Decision tree for CAD diagnosis including strategy 1 and strategy 2 used to design the model. 
CAD), combined with the complete anatomical information on the coronary arteries. These patients with a relevant ischemia burden are the primary candidates for revascularizations according the most recent guidelines [10]. This ischemia burden is defined in the newest guidelines as a positive FFR of proximal coronary vessels $[9,10]$ or by $\geq 2$ segments with ischemia on perfusion-CMR [10]. The effectiveness criterion for strategy 1 is achieved by a positive perfusion-CMR study ( $\geq 2$ segments ischemic, see also Table 1), which is complemented by a complete anatomical information provided by a CXA examination in patients positive for ischemia. For strategy 2, the effectiveness criterion is achieved by the detection of a stenosis $\geq 50 \%$ in CXA combined with an FFR $\leq 0.75$ (= significant CAD). By assumption, invasive CXA and FFR were the reference tests with an assumed 100\% diagnostic accuracy (Table 1). For the calculation of hemodynamically significant lesions by the $\mathrm{CMR}+\mathrm{CXA}$ strategy, per-patient sensitivities $\left(\mathrm{Sn}_{\mathrm{CMR}}=\right.$ $0.88)$ and specificities $\left(\mathrm{Sp}_{\mathrm{CMR}}=0.90\right)$ were considered as determined by Rieber et al. who compared ischemia on CMR (i.e. $\geq 2$ segment positive) versus FFR $\leq 0.75$ as the reference for ischemia [31]. Cost-effectiveness is defined as the costs per effect which is calculated as the ratio between the total costs and the number of patients correctly diagnosed as having one or more hemodynamically significant coronary lesion(s) (true positive). Also, the costs of complications in patients with a false negative diagnosis are included in the cost-effectiveness ratio.

In this study, the objective of the analysis was to compare cost-effectiveness ratios from the third party payer perspective and not to assess the general impact of CAD detection on the society welfare.

Table 1 Test performance parameters used in the effectiveness calculations

\begin{tabular}{|c|c|c|}
\hline Abbreviation & Description & $\begin{array}{l}\text { Parameter } \\
\text { value }\end{array}$ \\
\hline \multicolumn{3}{|c|}{$\begin{array}{l}\text { Test to yield anatomical information (= detection of diameter } \\
\text { reduction } \geq 50 \% \text { ) }\end{array}$} \\
\hline $\mathrm{Sn}_{\mathrm{CXA}}$ & Sensitivity of CXA & 1 \\
\hline $\mathrm{Sp}_{\mathrm{CXA}}$ & Specificity of CXA & 1 \\
\hline $\mathrm{Sn}_{\mathrm{FFR}}$ & Sensitivity of FFR & 1 \\
\hline $\mathrm{Sp}_{\mathrm{FFR}}$ & Specificity of FFR & 1 \\
\hline $\mathbf{R}_{\text {CXA }}$ & Rate of complications with invasive CXA & $0.0005[27]$ \\
\hline \multicolumn{3}{|c|}{ Test to yield ischemia information (=detection of myocardial ischemia) } \\
\hline $\mathrm{Sn}_{\mathrm{CMR}}$ & $\begin{array}{l}\text { Sensitivity of CMR ( } \geq 2 \text { segments positive } \\
\text { vs FFR } \leq 0.75 \text { ) }\end{array}$ & $0.88[31]$ \\
\hline $\mathrm{Sp}_{\mathrm{CMR}}$ & $\begin{array}{l}\text { Specificity of CMR ( } \geq 2 \text { segments positive } \\
\text { vs FFR } \leq 0.75 \text { ) }\end{array}$ & $0.90[31]$ \\
\hline NDx & Non diagnostic rate for CMR & $0.05[32]$ \\
\hline $\mathbf{R}_{\mathbf{F}}$ & $\begin{array}{l}\text { Rate of complications per 10-year } \\
\text { follow-up period for patients with CAD } \\
\text { and false-negative tests }\end{array}$ & $0.15[27]$ \\
\hline
\end{tabular}

When performing cost-effectiveness analysis, a wide variety of factors and parameters related to the costs and the performances of the tests have to be considered. The model must be able to take into account the costs associated with false-positive results (i.e. costs of unnecessary diagnostic tests or treatments) as well as the costs associated with false negative results (i.e. costs of complications because of inappropriate management of the disease). To this end, data from the published literature on the performances of tests (sensitivities, specificities and rate of nondiagnostic examinations) and the complication rates were used (Table 1).

To appropriately model strategy 2 (CXA + FFR), the portion of patients with diameter stenoses $\geq 50 \%$ on CXA having ischemia in FFR must be known. In other words, the relationship between the probability of stenoses $\geq 50 \%$ on CXA $\left(\mathrm{P}_{\text {sten }}\right)$ and the probability of having ischemia on FFR $\left(\mathrm{P}_{\text {isch }}\right)$ must be known. In order to assess this relationship, we used published data from 5 recent articles (see Additional file 1: Section A1 for details).

Definition of costs and calculations of the costs per effect The costs of a diagnostic strategy consist of first-line test costs and subsequent costs. The first-line test costs are the fees $\left(\mathrm{F}_{\mathrm{t}}\right)$ for the CMR and CXA tests. Subsequent costs were costs of additional tests (i.e. in case of nondiagnostic CMR or unnecessary diagnostic tests in case of false-positive results), costs of major complications induced by the diagnostic procedure or resulting from mis-diagnosis of a patient (e.g. as false negative patients are at risk to have complications per 10-years follow-up because of inappropriate management of the disease). Due to the non-invasive nature of CMR and recent results showing that no severe complications occurred in $>17,000 \mathrm{CMR}$ examinations (i.e. 7 mild reactions in $>7,200$ stress CMR examinations) in the EuroCMR registry [33] and in large multicenter trials [19], we assumed that CMR is not associated with direct procedure-related major complications. As an anaphylactic shock is extremely rare and may occur after administration of both MR- and CXA-related contrast media, this complication was not considered in the analysis. We assumed that a potential complication associated with either a diagnostic CXA or an untreated hemodynamically significant lesion (i.e. false negatives) is a myocardial infarction (MI). Costs for this complication (hereafter $\mathrm{C}$ ) included medical costs associated with the complications and accounted for a PCI, a hospital stay of one week, and a rehabilitation period of 4 weeks. The risk of developing malignancies induced by radiation exposure was not incorporated into the model. Future complications-related costs were discounted annually at a rate of $3 \%$ [34]. 
The total costs of a diagnostic algorithm were calculated as the sum of direct costs and subsequent costs multiplied by the respective number of patients. The cost-effectiveness ratios were calculated for patient cohorts with different pretest likelihoods ranging from $10 \%$ to $100 \%$.

The cost-effectiveness ratios were calculated as follows:

$$
\text { Cost }- \text { effectiveness Ratio }=\frac{\text { Direct cost }+ \text { subsequent costs }}{\text { effectiveness }}
$$

Calculations of the direct and subsequent costs and the detailed equations are presented in the Additional file 1: Section A2.

\section{Evaluation of the costs in each country}

The analyses were conducted from the third party payer perspective in 4 countries. We used 2012 and 2013 costs data in Swiss Francs (CHF) for Switzerland, in Euros $(€)$ for Germany, in Pounds $(£)$ for the United Kingdom (UK), and in American Dollars (US \$) for the United States. The Additional file 2 provides a brief description on how the costs were derived for each country.

\section{Sensitivity analysis}

Due to the uncertainty of the data used and the numerous assumptions (parameter values) made in these calculations, a sensitivity analysis was performed to test the robustness of the model. Thus, the model was re-run with 1) changes in the costs of the tests and of the complications, 2) changes in the rates of complications associated with CXA, 3) changes in the accuracy of the CMR test, and 4) change in the threshold of FFR to detect ischemia $(<0.75$ vs $<0.80$; regarding the method used refer to Additional file 1). In order to understand the impact of each parameter in the model they were changed one by one in the repeated calculations (for details, see the figures related to the sensitivity analyses in the Results section).

\section{Results}

Effect of the pretest likelihood of significant CAD on effectiveness and on costs of the two strategies

Figure 2 shows the effect of the pretest likelihood of significant CAD on effectiveness. The proportion of patients with CAD for whom a correct diagnosis is made by the CMR-based strategy depends on its sensitivity, specificity, and the rate of non-diagnostic CMR examinations (Additional file 1: Section A2). As CXA and FFR are assumed to be the reference with $100 \%$ accuracy, its advantage compared to CMR increases as $\mathrm{P}_{\text {isch }}$ increases. We derived that the difference between the 2 strategies slightly decreases with an increase of the rate of patients with non-diagnostic CMR tests (NDx). In the model, the NDx patients after CMR are oriented to strategy 2 in order to achieve $100 \%$ accuracy in these cross-over patients.

Figure 3 shows the effect of pretest likelihood of significant CAD on cost (example for the Swiss health care system). The cost per patient tested increases with increasing pre-test likelihood of significant CAD for both strategies. The costs for CXA + FFR slightly increase as the need for FFR increases with increasing

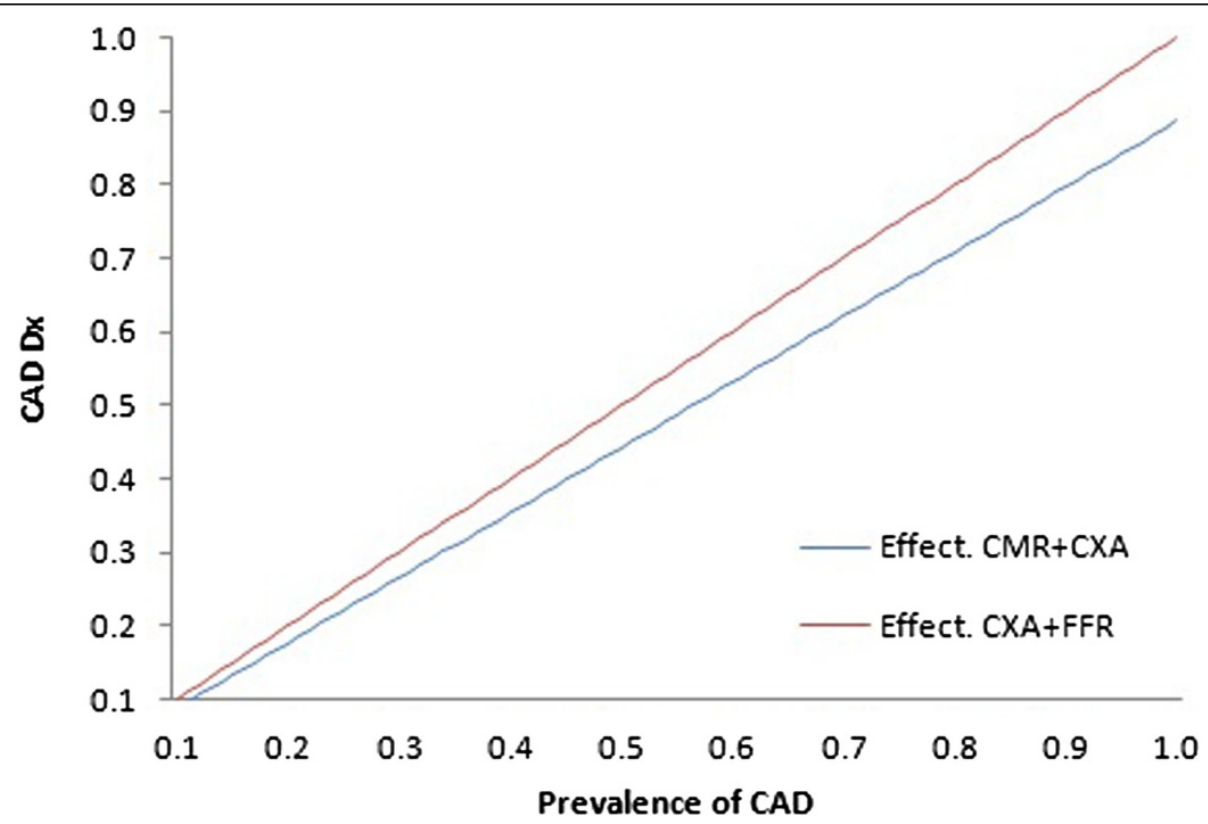

Figure 2 Example for the Swiss health care system: Proportion of patients with suspected CAD correctly diagnosed (CAD Dx) by the CMR + CXA and CXA + FFR strategies in relation to pre-test likelihood of significant CAD ( $\left.P_{\text {isch. }}\right)$. 


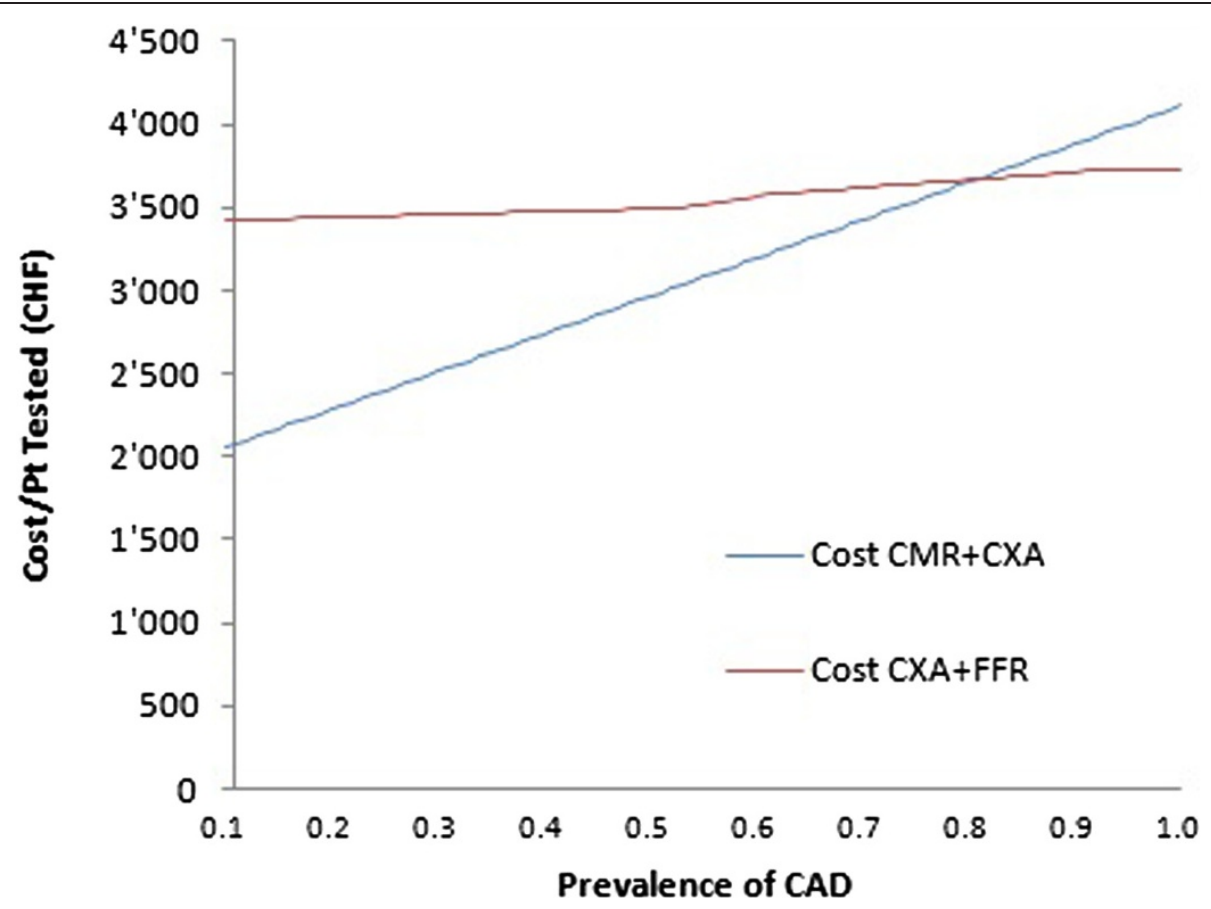

Figure 3 Costs per patient $(\mathrm{Pt})$ tested in relation to the pre-test likelihood of significant $C A D\left(=P_{i s c h}\right)$ for both strategies.

prevalence of significant CAD. For the CMR + CXA strategy the costs increase steeply with increasing pretest likelihood of significant CAD, since patients positive for ischemia on CMR have to undergo CXA. The two strategies are equally costly for a prevalence of significant CAD of 0.87 (Figure 4). The value for such a crossing point, within the range of $\mathrm{P}_{\text {isch }}(0-1.0)$ depends on the relative costs of the tests and the accuracy of the CMR test (NDx and $\mathrm{Sn}_{\mathrm{CMR}}$ and $\mathrm{Sp}_{\mathrm{CMR}}$ ) (see formulas of costs).

When CXA is considered as inpatient test, the cost per patient tested with strategy $1(\mathrm{CMR}+\mathrm{CXA})$ is lower than the cost per patient tested with strategy 2 (CXA + FFR) at any level of pre-test-likelihood of CAD.

\section{Comparison of the cost per effect and of cost- effectiveness for the two strategies}

Figure 4 shows the cost per effect, i.e. the cost per patient correctly diagnosed for significant $C A D$ at various levels of CAD prevalence in the 4 countries. We observe that the cost per effect decreases hyperbolically for both strategies as the pretest likelihood increases. The hyperbolic relationship between the prevalence of significant $\mathrm{CAD}$ and the costs per patient correctly diagnosed shows the high cost per effect in the patient population with low prevalence of significant CAD (= low $\mathrm{P}_{\text {isch }}$ values). The costs per effect at low values of $P_{\text {isch }}$ are higher for strategy $2(\mathrm{CX}+\mathrm{FFR})$ than for strategy $1(\mathrm{CMR}+\mathrm{CXA})$.
By assuming that all tests are outpatient tests, both strategies are equally cost-effective at a pretest likelihood of $62 \%$ in Switzerland, $65 \%$ in Germany, $83 \%$ in the UK, and $82 \%$ in the United States with costs of CHF 5,794, $€ 1,517, £ 2,680$, and $\$ 2,179$ per patient correctly diagnosed, respectively. Below this threshold, CMR + CXA shows lower costs per patient correctly diagnosed than CXA + FFR. When the CXA test is performed as an inpatient examination, the crossing point of the two curves shifts towards the right to a prevalence of significant CAD of $77 \%$ with costs of CHF 6,819 in Switzerland, to $90 \%$ with costs of $€ 2$ ' 847 in Germany, to $93 \%$ with costs of $£ 4,633$ in the UK, and to $94 \%$ with costs of $\$ 3,849$ in the US.

\section{Sensitivity analyses}

Following a reduction of the sensitivity of the CMR examination by $10 \%$ the crossing point shifted to the left by $16,20,14$, and 30 percentage points for the Swiss, the German, the UK, and the US health care systems, respectively. An increase of the CMR sensitivity by $10 \%$ shifted the crossing point to the right by 15,19 , and 12 percentage points for the Swiss, the German, and the UK health care systems, respectively. There is no crossing point for $\mathrm{P}_{\text {isch }}<1$ for the US health care system (Figures 5, 6, 7 and 8), i.e. the costs of the CMR strategy are lower than those of the CXA strategy in the US system irrespectively of the pre-test likelihood of CAD. 

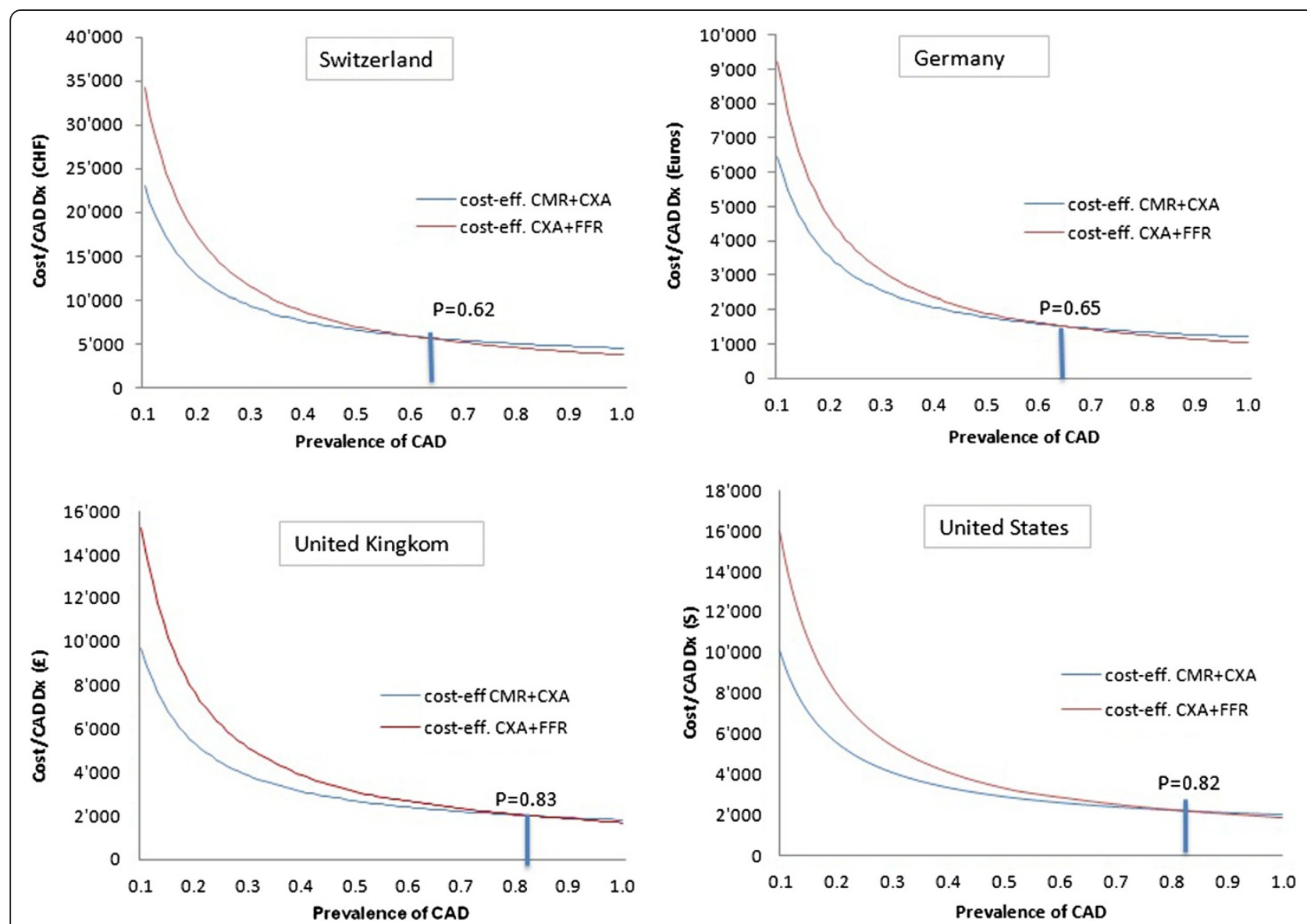

Figure 4 Results for outpatient procedures performed in the 4 countries. Costs per effect (= cost-effectiveness) for both strategies in relation to the prevalence of significant $C A D\left(=P_{\text {isch }}\right)$.

Changing the specificity of CMR had a minor influence on the crossing point for all health care systems assessed. This was also the case for the other variables tested in the sensitivity analysis except the complications rate. The sensitivity analysis shows that the rate for complications caused by mis-diagnosed CAD, i.e. a lack of detecting $\mathrm{CAD}$, is associated with relevant costeffectiveness changes at least in the US system. If the rate of complications in false-negative patients by CMR is doubled the crossing point is shifted to the left by 10 , 12,6 , and 23 percentage points in the Swiss, German, UK, and US systems, respectively.

An increase of the FFR threshold to $<0.80$ did not substantially influence the cost-effectiveness results as shown in (Figures 5, 6, 7 and 8). The crossing point shifted to the left by 2 or 3 percentage points for the 4 health care systems.

\section{Discussion}

The main findings of this study can be summarized as follows: 1) In all four health care systems analyzed, the cost effectiveness ratio decreases hyperbolically for both diagnostic strategies with an increasing prevalence of hemodynamically significant coronary lesions, i.e. with an increasing prevalence of significant CAD. 2) The increase in the cost-effectiveness for strategy 2, i.e. CXA + FFR, with increasing prevalence of significant CAD is more pronounced than that of the primarily noninvasive CMR + CXA strategy, implying that there is a threshold value of CAD prevalence where strategy 2 becomes more cost-effective than strategy 1 . and 3) The crossing point indicating an equal cost-effectiveness for the 2 strategies varied for the 4 countries examined. In Switzerland, strategy 1 , i.e. CMR + CXA, is more costeffective than strategy 2 below a CAD prevalence of $62 \%$. In the German, UK, and US health care systems, a higher cost-effectiveness for CMR + CXA is given for a CAD prevalence below $65 \%, 83 \%$, and $82 \%$, respectively.

CAD prevalence for optimum cost-effectiveness of various strategies and current utilization of resources

Current clinical practice guidelines recommend proceeding to PCI only, if relevant myocardial ischemia in symptomatic patients is present $[9,10]$. Therefore, it appears 


\begin{tabular}{|c|c|c|c|c|c|c|c|c|}
\hline Swiss context & $\begin{array}{c}\text { Standard } \\
\text { Value }\end{array}$ & $\begin{array}{c}\text { Prev of CAD where } \\
\text { both strategies are } \\
\text { equally cost- } \\
\text { effective }\end{array}$ & $\begin{array}{l}\text { New value } \\
(-10 \% \text { for } \\
\text { fees })\end{array}$ & $\begin{array}{c}\text { Prev of CAD where } \\
\text { both strategies are } \\
\text { equally cost- } \\
\text { effective }\end{array}$ & $\begin{array}{c}\text { Cost value in } \\
\mathrm{CHF} \text { at the } \\
\text { crossing } \\
\text { point }\end{array}$ & $\begin{array}{c}\text { New value } \\
(+10 \% \text { for } \\
\text { fees) }\end{array}$ & $\begin{array}{c}\text { Prev of CAD where } \\
\text { both strategies are } \\
\text { equally cost- } \\
\text { effective }\end{array}$ & $\begin{array}{l}\text { Cost value in } \\
\text { CHF at the } \\
\text { crossing point }\end{array}$ \\
\hline Fee for FFR & $1 ' 212$ & \multirow{12}{*}{$\begin{array}{l}\text { Pisch }=0.619 \\
(\text { CHF 5'794) }\end{array}$} & \multicolumn{2}{|l|}{$1^{\prime} 091$} & 6'155 & \multicolumn{2}{|l|}{ 1'334 } & $5 ' 552$ \\
\hline Fee for CMR in CHF & $1^{\prime} 420$ & & \multicolumn{2}{|r|}{0.698} & $5^{\prime} 186$ & \multicolumn{2}{|l|}{ 1'562 } & $6^{\prime} 743$ \\
\hline Fee for CXA (outpatient) in CHF & 2'508 & & \multicolumn{2}{|l|}{$2^{\prime 2} 257$} & $5 ' 875$ & \multicolumn{2}{|r|}{0.654} & $5 ' 886$ \\
\hline \multirow[t]{3}{*}{ Costs for complications } & 23,083 & & \multicolumn{2}{|l|}{$20^{\prime} 778$} & $5 ' 709$ & \multicolumn{2}{|l|}{25,396} & $5 ' 899$ \\
\hline & & & \multicolumn{3}{|c|}{$\begin{array}{l}\text { if all (above) new cost values are considered } \\
\mathbf{P}_{\text {isch }}=0.619 \text { at a cost per effect of CHF 5'215 }\end{array}$} & \multicolumn{3}{|c|}{$\begin{array}{c}\text { if all above new cost values are considered } \\
\text { Pisch }=0.619 \text { at a cost per effect of } C H F 6^{\prime} 372\end{array}$} \\
\hline & $\begin{array}{c}\text { Standard } \\
\text { Value }\end{array}$ & & New value & $\begin{array}{c}\text { Prev of CAD where } \\
\text { both strategies are } \\
\text { equally cost- } \\
\text { effective }\end{array}$ & $\begin{array}{c}\text { Cost value in } \\
\text { CHF at the } \\
\text { crossing } \\
\text { point }\end{array}$ & New value & $\begin{array}{c}\text { Prev of CAD where } \\
\text { both strategies are } \\
\text { equally cost- } \\
\text { effective }\end{array}$ & $\begin{array}{l}\text { Cost value in } \\
\text { CHF at the } \\
\text { crossing point }\end{array}$ \\
\hline Accuracy CMR (NonDx) & 0.05 & & \multicolumn{2}{|r|}{0.634} & $5^{\prime} 660$ & \multicolumn{2}{|r|}{0.560} & 6.300 \\
\hline Sensitivity CMR & 0.88 & & \multicolumn{2}{|r|}{0.456} & 7'634 & \multicolumn{2}{|r|}{0.776} & $4^{\prime} 709$ \\
\hline Specificity CMR & 0.9 & & \multicolumn{2}{|r|}{0.573} & $6^{\prime} 179$ & \multicolumn{2}{|r|}{0.646} & $5 ' 562$ \\
\hline Risk associated with $\mathrm{CXA}\left(\mathrm{R}_{\mathrm{CX} A}\right)$ & 0.0005 & & \multicolumn{2}{|l|}{0.001} & $5 ' 800$ & \multicolumn{2}{|l|}{ - } & - \\
\hline $\begin{array}{l}\text { Risk of complications per } 10 \text {-year follow- } \\
\text { up for patients with CAD \& false } \\
\text { negative results }\end{array}$ & 0.15 & & \multicolumn{2}{|r|}{0.654} & $5^{\prime} 503$ & \multicolumn{2}{|r|}{0.514} & 6'799 \\
\hline FFR threshold & 0.75 & & 0.80 & 0.584 & 5'984 & - & - & - \\
\hline
\end{tabular}

Figure 5 Sensitivity analysis: Switzerland.

reasonable to incorporate FFR testing or perfusion CMR for ischemia assessment into models that assess the costeffectiveness of various strategies suggested for a CAD work-up. Moreover, an FFR-guided PCI approach was shown to be more cost-effective than a simple anatomy- guided, i.e. CXA-based PCI approach [7]. The current results show for all four health care systems assessed, that the pre-test likelihood of CAD is a major factor that influences the cost-effectiveness of a CAD work-up. This is in line with the fact that benefits from diagnostic tests

\begin{tabular}{|c|c|c|c|c|c|c|c|c|}
\hline German context & $\begin{array}{c}\text { Standard } \\
\text { Value }\end{array}$ & $\begin{array}{l}\text { Prev of CAD where } \\
\text { both strategies are } \\
\text { equally cost- } \\
\text { effective }\end{array}$ & $\begin{array}{l}\text { New value } \\
\text { (-10\% for } \\
\text { fees) }\end{array}$ & $\begin{array}{c}\text { Prev of CAD where } \\
\text { both strategies are } \\
\text { equally cost- } \\
\text { effective }\end{array}$ & $\begin{array}{c}\text { Cost value in } \\
€ \text { at the } \\
\text { crossing } \\
\text { point }\end{array}$ & $\begin{array}{c}\text { New value } \\
(+10 \% \text { for } \\
\text { fees })\end{array}$ & $\begin{array}{l}\text { Prev of CAD } \\
\text { where both } \\
\text { strategies are } \\
\text { equally cost- } \\
\text { effective }\end{array}$ & $\begin{array}{l}\text { Cost value in } € \text { at } \\
\text { the crossing } \\
\text { point }\end{array}$ \\
\hline \multirow{7}{*}{$\begin{array}{l}\text { Fee for FFR in } € \\
\text { Fee for CMR in } € \\
\text { Fee for CXA (outpatient) in } € \\
\text { Costs for complications }\end{array}$} & 397 & \multirow{13}{*}{$\begin{array}{c}P_{\text {isch }}=0.647 \\
(€ 1 ' 517)\end{array}$} & \multicolumn{2}{|r|}{0.563} & $1^{\prime} 647$ & \multicolumn{2}{|r|}{0.720} & $1^{\prime} 429$ \\
\hline & 410 & & \multicolumn{2}{|r|}{0.746} & $1 ' 336$ & \multicolumn{2}{|r|}{0.521} & $1 ' 822$ \\
\hline & 626 & & \multicolumn{2}{|r|}{0.594} & $1 ' 527$ & \multicolumn{2}{|r|}{0.682} & $1^{\prime} 538$ \\
\hline & $5 ’ 976$ & & 5,378 & 0.659 & $1^{\prime} 492$ & \multicolumn{2}{|r|}{0.635} & $1 ' 542$ \\
\hline & & & \multicolumn{3}{|c|}{$\begin{array}{l}\text { if all (above) new cost values are considered } \\
\mathbf{P}_{\text {isch }}=0.647 \text { at a cost per effect of Euros 1'364 }\end{array}$} & \multicolumn{3}{|c|}{$\begin{array}{l}\text { if all above new cost values are considered } \\
\mathbf{P}_{\text {isch }}=0.647 \text { at a cost per effect of Euros 1'669 }\end{array}$} \\
\hline & & & & & & & & \\
\hline & $\begin{array}{l}\text { Standard } \\
\text { Value }\end{array}$ & & New value & $\begin{array}{c}\text { Prev of CAD where } \\
\text { both strategies are } \\
\text { equally cost- } \\
\text { effective }\end{array}$ & $\begin{array}{c}\text { Cost value in } \\
€ \text { at the } \\
\text { crossing } \\
\text { point }\end{array}$ & New value & $\begin{array}{l}\text { Prev of CAD } \\
\text { where both } \\
\text { strategies are } \\
\text { equally cost- } \\
\text { effective } \\
\end{array}$ & $\begin{array}{c}\text { Cost value in } € \text { at } \\
\text { the crossing } \\
\text { point }\end{array}$ \\
\hline Accuracy CMR (NonDx) & 0.05 & & 0.03 & 0.667 & $1^{\prime} 476$ & 0.10 & 0.580 & $1^{\prime} 665$ \\
\hline Sensitivity CMR & 0.88 & & 0.80 & 0.455 & $2{ }^{\prime} 075$ & 0.96 & 0.838 & $1 ' 206$ \\
\hline Specificity CMR & 0.90 & & 0.84 & 0.612 & $1 ' 594$ & 0.96 & 0.675 & $1^{\prime} 461$ \\
\hline Risk associated with CXA ( $\left.\mathrm{R}_{\mathrm{CXA}}\right)$ & 0.0005 & & \multicolumn{2}{|l|}{0.001} & $1 ' 518$ & \multicolumn{2}{|l|}{-} & - \\
\hline $\begin{array}{l}\text { Risk of complications per 10-year } \\
\text { follow-up for patients with CAD \& } \\
\text { false negative results }\end{array}$ & 0.15 & & 0.10 & 0.689 & $1^{\prime} 434$ & 0.30 & 0.523 & $1^{\prime} 814$ \\
\hline FFR threshold & 0.75 & & 0.80 & 0.624 & 1'549 & & & \\
\hline
\end{tabular}

Figure 6 Sensitivity analysis: Germany. 


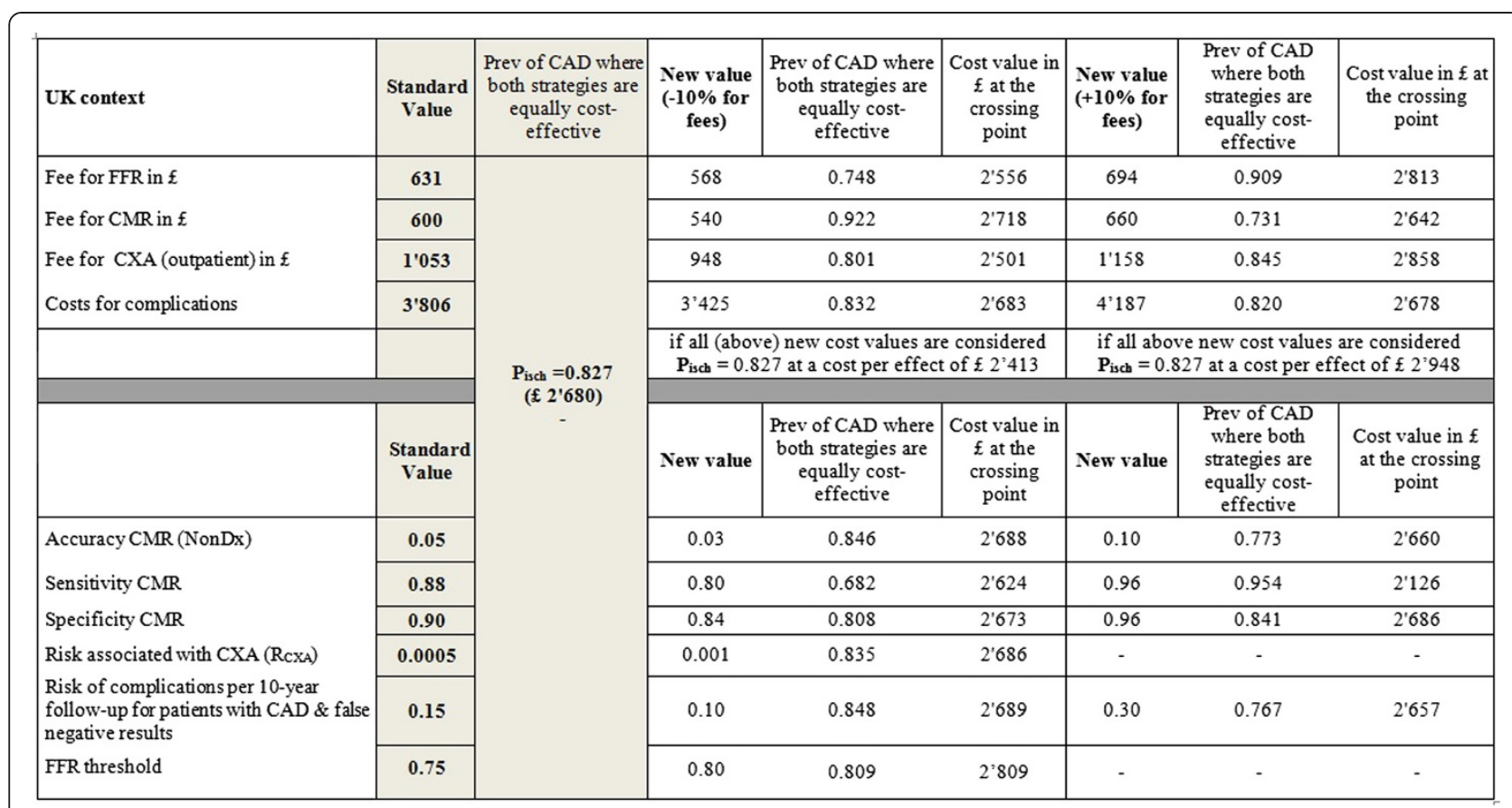

Figure 7 Sensitivity analysis: The United Kingdom.

\begin{tabular}{|c|c|c|c|c|c|c|c|c|}
\hline US context & $\begin{array}{l}\text { Standard } \\
\text { Value }\end{array}$ & $\begin{array}{l}\text { Prev of CAD } \\
\text { where both } \\
\text { strategies are } \\
\text { equally cost- } \\
\text { effective }\end{array}$ & $\begin{array}{l}\text { New value } \\
(-10 \% \text { for } \\
\text { fees })\end{array}$ & $\begin{array}{l}\text { Prev of CAD } \\
\text { where both } \\
\text { strategies are } \\
\text { equally cost- } \\
\text { effective }\end{array}$ & $\begin{array}{c}\text { Cost value in } € \\
\text { at the crossing } \\
\text { point }\end{array}$ & $\begin{array}{l}\text { New value } \\
(+10 \% \text { for } \\
\text { fees })\end{array}$ & $\begin{array}{l}\text { Prev of CAD } \\
\text { where both } \\
\text { strategies are } \\
\text { equally cost- } \\
\text { effective }\end{array}$ & $\begin{array}{c}\text { Cost value in } € \\
\text { at the crossing } \\
\text { point }\end{array}$ \\
\hline Fee for FFR in $\$$ & 888 & \multirow{13}{*}{$\begin{array}{l}\text { Pisch }=0.820 \\
\quad(\$ 2 \text { 2'179) }\end{array}$} & \multicolumn{2}{|r|}{0.702} & $2^{\prime} 370$ & \multicolumn{2}{|r|}{0.917} & $2^{\prime} 078$ \\
\hline Fee for CMR in $\$$ & 634 & & \multicolumn{2}{|r|}{0.915} & $1 ' 986$ & \multicolumn{2}{|r|}{0.723} & $2^{\prime} 424$ \\
\hline Fee for CXA (outpatient) in $\$$ & 929 & & 836 & 0.798 & $2^{\prime} 112$ & \multicolumn{2}{|l|}{$1^{\prime} 022$} & $2 ' 252$ \\
\hline Costs for complications & $19 ' 105$ & & $17^{\prime} 195$ & 0.850 & $2^{\prime} 110$ & \multicolumn{2}{|l|}{$21^{\prime} 016$} & $2^{\prime} 248$ \\
\hline & & & \multicolumn{3}{|c|}{$\begin{array}{l}\text { if all (above) new cost values are considered PCAD } \\
\quad=0.820 \text { at a cost per effect of } \$ 1^{\prime} 962\end{array}$} & \multicolumn{3}{|c|}{$\begin{array}{l}\text { if all (above) new cost values are considered PCAD } \\
\quad=0.820 \text { at a cost per effect of } \$ 2^{\prime} 396\end{array}$} \\
\hline \multicolumn{2}{|c|}{ 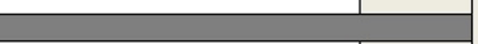 } & & \multicolumn{3}{|c|}{\begin{tabular}{|l|l|l|}
\multicolumn{3}{|c|}{} \\
\end{tabular}} & & & \\
\hline & $\begin{array}{l}\text { Standard } \\
\text { Value }\end{array}$ & & New value & $\begin{array}{l}\text { Prev of } \mathrm{CAD} \text { where } \\
\text { both strategies are } \\
\text { equally cost-effective }\end{array}$ & $\begin{array}{c}\text { Cost value in } € \\
\text { at the crossing } \\
\text { point }\end{array}$ & New value & $\begin{array}{l}\text { Prev of CAD } \\
\text { where both } \\
\text { strategies are } \\
\text { equally cost- } \\
\text { effective }\end{array}$ & $\begin{array}{c}\text { Cost value in } € \\
\text { at the crossing } \\
\text { point }\end{array}$ \\
\hline Accuracy for CMR (NonDx) & 0.05 & & 0.03 & 0.839 & $2^{\prime} 135$ & 0.10 & 0.765 & $2^{\prime} 308$ \\
\hline Sensibility CMR & 0.88 & & 0.80 & 0.517 & 3'194 & 0.96 & \multicolumn{2}{|c|}{ No crossing point for $P<1$} \\
\hline Specificity CMR & 0.9 & & 0.84 & 0.803 & $2^{\prime} 216$ & 0.96 & 0.833 & $2^{\prime} 149$ \\
\hline Risk associated with CXA (RCXA) & 0.0005 & & 0.001 & 0.821 & $2^{\prime} 186$ & $\mathrm{x}$ & $\mathrm{x}$ & $\mathrm{x}$ \\
\hline $\begin{array}{l}\text { Risk of complications per 10-year } \\
\text { follow-up for patients with CAD \& } \\
\text { false negative results }\end{array}$ & 0.15 & & 0.1 & 0.934 & $1 ' 951$ & 0.3 & 0.587 & $2^{\prime} 886$ \\
\hline FFR threshold & 0.75 & & 0.80 & 0.795 & $2^{\prime} 211$ & & & \\
\hline
\end{tabular}

Figure 8 Sensitivity analysis: The United States. 
depend on its performance but also on the prevalence of the disease within the evaluated population [35]. According to the current analyses a non-invasive CMR-guided approach is cost-effective for patients with an intermediate pre-test likelihood of disease, which is in line with most guidelines defining intermediate pre-test probabilities as $20-80 \%$. Interestingly, in the US $62 \%$ of elective CXA examinations performed in a large sample of approximately 400,000 patients were found to be negative for CAD (stenoses $<50 \%$ diameter reduction) [18], indicating that in the US the pre-test probability of CAD in daily routine is as low as $\sim 38 \%$ which is substantially lower than the calculated threshold of $82 \%$. Similarly, in the UK more than $58 \%$ of CXA examinations did not result in PCI or CABG procedures [36] indicating that currently, the pre-test likelihood of significant CAD of patients referred for CXA of $42 \%$ is substantially lower than $83 \%$ calculated for the UK. In the German health care system, the optimum pre-test likelihood of CAD for a CMR-based strategy is below $65 \%$. However, in 2008 , only $43 \%$ of patients after CXA were revascularized [17], indicating that an invasive approach was applied in a patient population with a relatively low CAD prevalence of approximately $43 \%$. Finally, in Switzerland, the theoretical threshold for a directly invasive strategy is at $62 \% \mathrm{CAD}$ prevalence. The portion of normal CXA studies ranged between $55 \%$ to $66 \%$ over the last 3 years [37], which translates into an approximated pre-test likelihood of significant CAD of $34-45 \%$ in Switzerland, thus, again still lower than the prevalence for a calculated optimal cost-effectiveness.

A cost analysis was recently performed based on the data of the German sample of the European CMR registry [38]. Cost savings of 50\% were calculated between a CMR strategy and an outpatient invasive CXA strategy which is in line with the fact, that the pre-test probability of CAD in this cohort was $27 \%$, i.e. well below the $65 \%$ level. The cost savings for this cohort reported in 2012 would be even higher considering that for these calculations costs for FFR were not yet included. Recently, a cost-effectiveness analysis for UK was performed based on the CE-MARC data [39]. For the prevalence of CAD of 39\% in CE-MARC [22], the diagnostic strategy based on CMR (preceded or not by a treadmill test) followed by CXA in case of ischemia on CMR was the most cost-effective strategy of all tested. This finding is well in line with the current calculations which suggest cost-effectiveness for the MR-based approach below a CAD prevalence of $83 \%$. In this context, it should be noted, that in the current study the threshold in favor of a CMR-guided work-up compared costeffectiveness versus an outpatient CXA + FFR strategy. If inpatient CXA is included into the model, the crossing point shifts towards $77 \%$ for Switzerland, and is $>90 \%$ for Germany, the UK and the US. This indicates that the inpatient CXA + FFR procedures can only compete with non-invasive CMR + CXA for very high rates of CAD prevalence. This result is of even greater importance if we note that in-patient CXA is performed in approximately $67 \%$ [40,41], 40\% [36], and 88\% [42], in the US, the UK, and the German system, respectively.

\section{Testing for ischemia by invasive vs non-invasive techniques}

For the current analyses, the FFR technique was assumed to represent the gold standard. The assumption appears justified in the light of a rapidly increasing number of studies confirming the high prognostic value of FFR-guided PCI [5,6,12-14].

At a first glance, a $\mathrm{Sn}_{\mathrm{CMR}}$ of $88 \%$ for ischemia detection (and of $\mathrm{Sn}_{\mathrm{CMR}}=80 \%$ in the sensitivity analysis) may appear relatively high. However, similar and even higher performances were reported with $\mathrm{Sn}_{\mathrm{CMR}} / \mathrm{Sp}_{\mathrm{CMR}}$ of $82 \% /$ 94\% [43] and $\mathrm{Sn}_{\mathrm{CMR}} / \mathrm{Sp}_{\mathrm{CMR}}$ of $91 \% / 94 \%$ [44]. Importantly, it should be taken into account that these $\mathrm{Sn}_{\mathrm{CMR}}$ for ischemia detection compare with an ischemia test, i.e. FFR. When lower sensitivities of CMR for ischemia detection are reported, they typically compare perfusionCMR with coronary anatomy. FFR is generally accepted as a useful tool to guide treatment in CAD patients, as it discriminates patients at risk for complications (FFRpositive) versus those with minimal risk (FFR-negative). In FFR-positive patients, complication rates (death and non-fatal MI) were $3.2 \%-11.1 \% / y$ versus $0.7-7.3 \% / y$ in FFR-negative patients $[5,6]$. In a recent registry-based FFR study, MI in the FFR non-ischemia group was $\sim 1 \% / y$ vs $\sim 1.9 \% / y$ in the ischemia group [12]. For perfusion CMR, similar discriminative power was observed in approximately 1,700 patients of the EuroCMR registry, with complications rates of $2.7 \% / y$ in CMR-positive patients, i.e. in patients with ischemia, versus $0.7 \% / y$ in CMR-negative patients [24]. Thus, with this evidence of a similar discriminative power for CMR and FFR, the assumption of FFR being the gold standard, and thus, classifying CMR results differing from FFR as incorrect, might induce a bias towards an underestimation of the cost-effectiveness of the CMR + CXA strategy.

\section{Limitations}

In the four countries, the unit costs for the cardiac examinations fed into the model may vary between different geographical regions and therefore, the results are representative for the entire health care systems under study, but not for smaller geographical regions. In the current model, no treatment costs were included. Correct absence of disease was not directly included in the criterion of effectiveness but the effect was captured indirectly through the costs of complications induced by false negative results. The model does not take into 
account intangible costs associated with cardiac death. This is because of the third-party-payer-perspective study design. For the US context, we decided to use costs for the material and a reimbursement of the physician to represent FFR costs similar to the approach used by Fearon et al. [7] as the current US reimbursement system does not consider costs for infrastructure nor material. The sensitivity analyses showed a rather moderate effect of prices for FFR on the cost-effectiveness shifting the crossing point by $\pm 6, \pm 8, \pm 8$, and \pm 11 percent points for the Swiss, the German, the UK, and the US system, respectively.

Finally, the modeling approach used here implies that some simplifications are built in and the decision process to revascularize or not is reduced to the presence or absence of hemodynamically significant stenoses. It does therefore not consider the clinical background of the patient, which is always important to guide treatment. Accordingly, the presented results might be helpful for trials planning whereas the use of the presented model with real CMR and FFR data acquired in ongoing trials [11] would most likely yield more relevant results.

\section{Conclusions}

With a focus on the latest imaging techniques to detect ischemia, this study shows to what extent the costeffectiveness of two strategies to diagnose hemodynamically significant coronary lesions, i.e. significant CAD, depends on the prevalence of the disease. The CMR + CXA strategy is more cost-effective than CXA + FFR below a CAD prevalence of $62 \%, 65 \%, 83 \%$, and $82 \%$ for the Swiss, the German, the UK, and the US health care systems, respectively. These findings may help the decision-making with regard to resource utilization.

\section{Additional files}

\section{Additional file 1: Section A1. The relationship FFR-Stenosis. Section A2.} Equations to estimate the costs and the effectiveness for each strategy.

Additional file 2: Brief description on how the costs were derived for each country.

\section{Abbreviations}

CAD: Coronary artery disease; CMR: Cardiovascular magnetic resonance; CXA: Invasive $x$-ray coronary angiography; FFR: Fractional flow reserve; $\mathrm{PCl}$ : Percutaneous coronary interventions.

\section{Competing interests}

The authors declare that they have no competing interests.

\section{Authors' contributions}

KM is responsible for the conception and design of the cost-effectiveness analysis; she performed the cost-effectiveness analysis, participated to the data collection and drafted the manuscript. DF participated to data collection and was involved in the calculations of the cost-effectiveness analysis. CP provided advices on the cost-effectiveness analysis. GP provided precisions on how the German health care system works and actively participated in the acquisition of required data in this context. SP provided information on how the UK health care system works and participated in the data acquisition in this context. AW provided explanations on how the US health care system works and participated in the data acquisition in this context. JBW provided explanations on how the Swiss health care system works. JS is responsible for the design of the study, participated to data collection and was involved in the interpretation of the results and drafting the manuscript; he critically revised its intellectual content. In addition, all authors provided helpful comments and relevant suggestions to improve the manuscript and its intellectual content; all authors read and approved the final manuscript.

\section{Acknowledgements}

This work forms part of the research areas of SEP contributing to the translational research portfolio of Barts Cardiovascular Biomedical Research Unit which is supported and funded by the National Institute for Health Research. This study was support by a grant of the Swiss Heart Foundation.

\section{Author details}

${ }^{1}$ Institute of Health Economics and Management (IEMS), University of Lausanne, Route de Chavannes 31, VIDY, 1015 Lausanne, Switzerland. ${ }^{2}$ Technology Assessment Unit (UET), University Hospital (CHUV), Lausanne, Switzerland. ${ }^{3}$ Klinik Agatharied, Akademisches Lehrkrankenhaus der LMU Munich, Hausham, Germany. ${ }^{4}$ National Institute for Health Research Cardiovascular Biomedical Research Unit at Barts, Queen Mary University of London, London, UK. ${ }^{5}$ Comprehensive Cardiology of Stamford and Greenwich, Stamford, CT 06902, USA. ${ }^{6}$ Cardiac MR Center, University Hospital (CHUV), Lausanne, Switzerland.

Received: 4 July 2013 Accepted: 17 December 2013 Published: 25 January 2014

\section{References}

1. Allender S, Scarborough P, O'Flaherty M, Capewell S. Patterns of coronary heart disease mortality over the 20th century in England and Wales: Possible plateaus in the rate of decline. BMC Public Health. 2008; 8:148.

2. Roger VL, Go AS, Lloyd-Jones DM, Benjamin EJ, Berry JD, Borden WB, Bravata DM, Dai S, Ford ES, Fox CS, Fullerton HJ, Gillespie C, Hailpern SM, Heit JA, Howard VJ, Kissela BM, Kittner SJ, Lackland DT, Lichtman JH, Lisabeth LD, Makuc DM, Marcus GM, Marelli A, Matchar DB, Moy CS, Mozaffarian D, Mussolino ME, Nichol G, Paynter NP, Soliman EZ, et al. Heart disease and stroke statistics-2012 update: a report from the American Heart Association. Circulation. 2012; 125:e2-220.

3. Bech GJ, De Bruyne B, Bonnier HJ, Bartunek J, Wijns W, Peels K, Heyndrickx GR, Koolen JJ, Pijls NH. Long-term follow-up after deferral of percutaneous transluminal coronary angioplasty of intermediate stenosis on the basis of coronary pressure measurement. J Am Coll Cardiol. 1998; 31:841-7.

4. Rieber J, Schiele TM, Koenig A, Erhard I, Segmiller T, Stempfle HU, Theisen K, Jung P, Siebert U, Klauss V. Long-term safety of therapy stratification in patients with intermediate coronary lesions based on intracoronary pressure measurements. Am J Cardiol. 2002; 90:1160-4.

5. Pijls NH, van Schaardenburgh P, Manoharan G, Boersma E, Bech JW, van't Veer M, Bär F, Hoorntje J, Koolen J, Wijns W, de Bruyne B. Percutaneous coronary intervention of functionally nonsignificant stenosis: 5-year follow-up of the DEFER Study. J Am Coll Cardiol. 2007; 49:2105-11.

6. Tonino PA, De Bruyne B, Pijls NH, Siebert U, Ikeno F, van' t Veer M, Klauss V, Manoharan G, Engstrøm T, Oldroyd KG, Ver Lee PN, MacCarthy PA, Fearon WF, FAME Study Investigators. Fractional flow reserve versus angiography for guiding percutaneous coronary intervention. N Engl J Med. 2009; 360:213-24.

7. Fearon WF, Bornschein B, Tonino PA, Gothe RM, Bruyne BD, Pijls NH, Siebert $U$, Fractional Flow Reserve Versus Angiography for Multivessel Evaluation (FAME) Study Investigators. Economic evaluation of fractional flow reserve-guided percutaneous coronary intervention in patients with multivessel disease. Circulation. 2010; 122:2545-50.

8. Brooks MM, Chaitman BR, Nesto RW, Hardison RM, Feit F, Gersh BJ, Krone RJ, Sako EY, Rogers WJ, Garber AJ, King SB 3rd, Davidson CJ, Ikeno F, Frye RL, BARI 2D Study Group. Clinical and Angiographic Risk Stratification and Differential Impact on Treatment Outcomes in the Bypass Angioplasty Revascularization Investigation 2 Diabetes (BARI 2D) Trial. Circulation. 2012; 126:2115-24.

9. Task Force on Myocardial Revascularization of the European Society of Cardiology (ESC) and the European Association for Cardio-Thoracic Surgery (EACTS), European Association for Percutaneous Cardiovascular Interventions (EAPCI), Wijns W, Kolh P, Danchin N, Di Mario C, Falk V, 
Folliguet T, Garg S, Huber K, James S, Knuuti J, Lopez-Sendon J, Marco J, Menicanti L, Ostojic M, Piepoli MF, Pirlet C, Pomar JL, Reifart N, Ribichini FL, Schalij MJ, Sergeant P, Serruys PW, Silber S, Sousa Uva M, Taggart D. Guidelines on myocardial revascularization: The Task Force on Myocardial Revascularization of the European Society of Cardiology (ESC) and the European Association for Cardio-Thoracic Surgery (EACTS). Eur Heart J. 2010; 31:2501-55.

10. Task Force Members, Montalescot G, Sechtem U, Achenbach S, Andreotti F, Arden C, Budaj A, Bugiardini R, Crea F, Cuisset T, Di Mario C, Ferreira JR, Gersh BJ, Gitt AK, Hulot JS, Marx N, Opie LH, Pfisterer M, Prescott E, Ruschitzka F, Sabaté M, Senior R, Taggart DP, van der Wall EE, Vrints CJ, ESC Committee for Practice Guidelines, Zamorano JL, Achenbach S, Baumgartner H, Bax JJ, et al. 2013 ESC guidelines on the management of stable coronary artery disease: The Task Force on the management of stable coronary artery disease of the European Society of Cardiology. Eur Heart J. 2013; 34:2949-3003.

11. Hussain S, Paul M, Plein S, McCann GP, Shah AM, Marber MS, Chiribiri A, Morton G, Redwood S, MacCarthy P, Schuster A, Ishida M, Westwood MA, Perera D, Nagel E. Design and rationale of the MR-INFORM study: stress perfusion cardiovascular magnetic resonance imaging to guide the management of patients with stable coronary artery disease. J Cardiovasc Magn Reson. 2012; 14:65.

12. Li J, Elrashidi MY, Flammer AJ, Lennon RJ, Bell MR, Holmes DR, Bresnahan JF, Rihal CS, Lerman LO, Lerman A. Long-term outcomes of fractional flow reserve-guided vs. angiography-guided percutaneous coronary intervention in contemporary practice. Eur Heart J. 2013; 34:1375-83,

13. De Bruyne B, Pijls NH, Kalesan B, Barbato E, Tonino PA, Piroth Z, Jagic N, Möbius-Winkler S, Rioufol G, Witt N, Kala P, MacCarthy P, Engström T, Oldroyd KG, Mavromatis K, Manoharan G, Verlee P, Frobert O, Curzen N, Johnson JB, Jüni P, Fearon WF, FAME 2 Trial Investigators. Fractional Flow Reserve-Guided PCI versus Medical Therapy in Stable Coronary Disease. N Engl I Med. 2012; 367:991-1001.

14. Bech GJ, De Bruyne B, Pijls NH, de Muinck ED, Hoorntje JC, Escaned J, Stella PR, Boersma E, Bartunek J, Koolen JJ, Wijns W. Fractional flow reserve to determine the appropriateness of angioplasty in moderate coronary stenosis: a randomized trial. Circulation. 2001; 103:2928-34.

15. Fearon WF, Tonino PA, de Bruyne B, Siebert U, Pijls NH, Investigators FS. Rationale and design of the Fractional Flow Reserve versus Angiography for Multivessel Evaluation (FAME) study. Am Heart J. 2007; 154:632-6.

16. Costa MA, Shoemaker S, Futamatsu H, Klassen C, Angiolillo DJ, Nguyen M, Siuciak A, Gilmore P, Zenni MM, Guzman L, Bass TA, Wilke N. Quantitative magnetic resonance perfusion imaging detects anatomic and physiologic coronary artery disease as measured by coronary angiography and fractional flow reserve. J Am Coll Cardiol. 2007; 50:514-22.

17. Horstkotte $D$, Wiemer $M$, van Buuren F. Performance figures of invasive cardiology in Germany 2006 and 2007 focussing on coronary artery disease. Clin Res Cardiol. 2011; 100:187-90.

18. Patel MR, Peterson ED, Dai D, Brennan JM, Redberg RF, Anderson HV, Brindis RG, Douglas PS. Low diagnostic yield of elective coronary angiography. $N$ Engl J Med. 2010; 362:886-95.

19. Schwitter J, Wacker CM, Wilke N, Al-Saadi N, Sauer E, Huettle K, Schönberg SO, Luchner A, Strohm O, Ahlstrom H, Dill T, Hoebel N, Simor T, MR-IMPACT Investigators. MR-IMPACT II: Magnetic Resonance Imaging for Myocardial Perfusion Assessment in Coronary artery disease Trial: perfusion-cardiac magnetic resonance vs. single-photon emission computed tomography for the detection of coronary artery disease: a comparative multicentre, multivendor trial. Eur Heart J. 2012; 34:775-81.

20. Schwitter J, Wacker CM, van Rossum AC, Lombardi M, Al-Saadi N, Ahlstrom H, Dill T, Larsson HB, Flamm SD, Marquardt M, Johansson L. MR-IMPACT: Magnetic Resonance Imaging for Myocardial Perfusion Assessment in Coronary Artery Disease Trial: Comparison of perfusion CMR with Single Photon Emission Computed Tomography for the Detection of Coronary Artery Disease in a Multicenter, Multivendor, Randomized Trial. Eur Heart J. 2008; 29:480-9.

21. Plein S, Schwitter J, Suerder D, Greenwood JP, Boesiger P, Kozerke S. $\mathrm{k}$-Space and time sensitivity encoding-accelerated myocardial perfusion MR imaging at 3.0 T: comparison with 1.5 T. Radiology. 2008; 249:493-500.

22. Greenwood JP, Maredia N, Younger JF, Brown JM, Nixon J, Everett CC, Bijsterveld P, Ridgway JP, Radjenovic A, Dickinson CJ, Ball SG, Plein S. Cardiovascular magnetic resonance and single-photon emission computed tomography for diagnosis of coronary heart disease (CE-MARC): a prospective trial. Lancet. 2012; 379:453-60.
23. Coelho-Filho O, Seabra L, Mongeon F, Abdullah S, Francis S, Blankstein R. Stress Myocardial perfusion Imaging by CMR provides strong prognostic values to cardiac events regardless of patient's sex. JACC CardiovasC Imaging. 2011; 4:850-61.

24. Bruder O, Wagner A, Lombardi M, Schwitter J, van Rossum A, Pilz G, Nothnagel D, Steen H, Petersen S, Nagel E, Prasad S, Schumm J, Greulich S, Cagnolo A, Monney P, Deluigi CC, Dill T, Frank H, Sabin G, Schneider S, Mahrholdt H. European Cardiovascular Magnetic Resonance (EuroCMR) registry-multinational results from 57 centers in 15 countries. J Cardiovasc Magn Reson. 2013; 15:9.

25. Jahnke C, Nagel E, Gebker R, Kokocinski T, Kelle S, Manka R, Fleck E, Paetsch I. Prognostic value of cardiac magnetic resonance stress tests: Adenosine stress perfusion and dobutamine stress wall motion imaging. Circulation. 2007; 115:1769-76.

26. Forrester J, Diamond G, Vas R, Charuzi Y, Silverberg R, Pichler M, Berman D. Early detection of coronary artery disease. Adv Cardiol. 1979; 26:1-14

27. Patterson RE, Eisner RL, Horowitz SF. Comparison of cost-effectiveness and utility of exercise ECG, single photon emission computed tomography, positron emission tomography, and coronary angiography for diagnosis of coronary artery disease. Circulation. 1995; 91:54-65.

28. Dorenkamp M, Bonaventura K, Sohns C, Becker CR, Leber AW. Direct costs and cost-effectiveness of dual-source computed tomography and invasive coronary angiography in patients with an intermediate pretest likelihood for coronary artery disease. Heart. 2011; 98:460-7.

29. Dewey M, Hamm B. Cost effectiveness of coronary angiography and calcium scoring using $\mathrm{CT}$ and stress MRI for diagnosis of coronary artery disease. Eur Radiol. 2006; 17:1301-9.

30. Boldt J, Leber AW, Bonaventura K, Sohns C, Stula M, Huppertz A, Haverkamp W, Dorenkamp M. Cost-effectiveness of cardiovascular magnetic resonance and single-photon emission computed tomography for diagnosis of coronary artery disease in Germany. J Cardiovasc Magn Reson. 2013; 15:30

31. Rieber J, Huber A, Erhard I, Mueller S, Schweyer M, Koenig A, Schiele TM, Theisen K, Siebert U, Schoenberg SO, Reiser M, Klauss V. Cardiac magnetic resonance perfusion imaging for the functional assessment of coronary artery disease: a comparison with coronary angiography and fractional flow reserve. Eur Heart J. 2006; 27:1465-71.

32. Bruder O, Schneider S, Nothnagel D, Dill T, Hombach V, Schulz-Menger J, Nagel E, Lombardi M, van Rossum AC, Wagner A, Schwitter J, Senges J, Sabin GV, Sechtem U, Mahrholdt H. EuroCMR (European Cardiovascular Magnetic Resonance) Registry: Results of the German Pilot Phase. J Am Coll Cardiol. 2009; 54:1457-66.

33. Bruder O, Schneider S, Nothnagel D, Pilz G, Lombardi M, Sinha A, Wagner A, Dill T, Frank H, van Rossum A, Schwitter J, Nagel E, Senges J, Sabin G, Sechtem U, Mahrholdt H. Acute Adverse Reactions to Gadolinium-Based Contrast Agents in CMR: Multicenter Experience With 17,767 Patients From the EuroCMR Registry. J Am Coll Cardiol - Cardiovasc Imaging. 2011; 4:1171-6.

34. Weinstein MC, Siegel JE, Gold MR, Kamlet MS, Russell LB, Recommendations of the Panel on Cost-effectiveness in Health and Medicine. JAMA. 1996; 276:1253-8.

35. Francis S, Daly C, Heydari B, Abbasi S, Shah R, Kwong R. Cost-effectiveness analysis for imaging techniques with a focus on cardiovascular magnetic resonance. J Cardiovasc Magn Reson. 2013; 15:52.

36. Gov.uk [internet] Department of Health, England, NHS reference costs: financial year 2011 to 2012. [Consulted 2013]. Available from https://www.gov.uk/ government/publications/nhs-reference-costs-financial-year-2011-to-2012.

37. Maeder M, et al. Swiss society of cardiology, Cardiovascular Medicine acts. Basel; 2011. 8-10 June 2011 (abstract).

38. Moschetti K, Muzzarelli S, Pinget C, Wagner A, Pilz G, Wasserfallen JB, Schulz-Menger J, Nothnagel D, Dill T, Frank H, Lombardi M, Bruder O, Mahrholdt H, Schwitter J. Cost evaluation of cardiovascular magnetic resonance versus coronary angiography for the diagnostic work-up of coronary artery disease: application of the European Cardiovascular Magnetic Resonance registry data to the German, United Kingdom, Swiss, and United States health care systems. J Cardiovasc Magn Reson. 2012; 14:35.

39. Walker S, Girardin F, McKenna C, Ball SG, Nixon J, Plein S, Greenwood JP, Sculpher M. Cost-effectiveness of cardiovascular magnetic resonance in the diagnosis of coronary heart disease: an economic evaluation using data from the CE-MARC study. Heart. 2013; 99(12):873-81. 
40. Cullen KA, Hall MJ, Golosinskiy A, Division of Health Care Statistics. Ambulatory Surgery in the United States. National Health Statistics Reports; 2006. 2009; Number 11.

41. Buie VC, Owings M, DeFrances C, Golosinskiy A. National Hospital Discharge Survey: 2006 summary. U.S. DEPARTMENT OF HEALTH AND HUMAN SERVICES National Center for Health Statistics. Vital Health Stat. 2010; 13:168.

42. Bruckenberger E, Winkler P. Herzbericht 2008 mit Transplantationschirurgie; 2009.

43. Lockie T, Ishida M, Perera D, Chiribiri A, De Silva K, Kozerke S, Marber M, Nagel E, Rezavi R, Redwood S, Plein S. High-resolution magnetic resonance myocardial perfusion imaging at 3.0-Tesla to detect hemodynamically significant coronary stenoses as determined by fractional flow reserve. J Am Coll Cardiol. 2011; 57:70-5.

44. Watkins S, McGeoch R, Lyne J, Steedman T, Good R, McLaughlin MJ, Cunningham T, Bezlyak V, Ford I, Dargie HJ, Oldroyd KG. Validation of Magnetic Resonance Myocardial Perfusion Imaging With Fractional Flow Reserve for the Detection of Significant Coronary Heart Disease. Circulation. 2009; 120:2207-13.

doi:10.1186/1532-429X-16-13

Cite this article as: Moschetti et al:: Comparative cost-effectiveness analyses of cardiovascular magnetic resonance and coronary angiography combined with fractional flow reserve for the diagnosis of coronary artery disease. Journal of Cardiovascular Magnetic Resonance 2014 16:13.

\section{Submit your next manuscript to BioMed Central and take full advantage of:}

- Convenient online submission

- Thorough peer review

- No space constraints or color figure charges

- Immediate publication on acceptance

- Inclusion in PubMed, CAS, Scopus and Google Scholar

- Research which is freely available for redistribution 